\title{
Da medicina do trabalho à saúde do trabalhador
}

\author{
René Mendes*, Elizabeth Costa Dias**
}

MENDES, R. \& DIAS, E.C. Da medicina do trabalho à saúde do trabalhador. Rev.Saúde públ., S.Paulo, 25: $341-9,1991$. Ensaio de revisão sobre a evolução dos conceitos e práticas da medicina do trabalho à saúde do trabalhador, passando pela saúde ocupacional. Busca-se responder às seguintes questões: quais as características básicas da medicina do trabalho (na sua origem e na sua evolução); como e por que evoluiu a medicina do trabalho para a saúde ocupacional; por que o modelo da saúde ocupacional se mostrou insuficiente; em que contexto surge a saúde do trabalhador; quais as principais características da saúde do trabalhador.

Descritores: Saúde ocupacional. Medicina ocupacional, história.

\section{Introdução}

O presente artigo constitui um ensaio de revisão sobre a evolução dos conceitos e práticas da medicina do trabalho à saúde do trabalhador, passando pela saúde ocupacional. O caráter de ensaio decorre da natureza preliminar deste exercício, pois que tal caminhada encontra-se em processo, e seu estudo está limitado pela falta do distanciamento histórico e de metodologias mais adequadas à sua abordagem.

Como artigo de revisão, tem sua base principal em documentos disponíveis, porém não se limita à literatura "cientifica", incipiente em estudos e trabalhos que abordem o tema proposto. Incorpora as discussões recentes deste processo que vêm se dando, no âmbito da academia e no conjunto da sociedade.

O presente trabalha busca responder a algumas questões básicas, tais como:

- Quais as principais caracteristicas da medicina do trabalho (na sua origem e na sua evolução)?

- Como e por que evoluiu a medicina do trabalho para a saúde ocupacional?

- Por que o modelo da saúde ocupacional se mostrou insuficiente?

- Em que contexto surge a saúde do trabalhador?

* Departamento de Medicina Preventiva e Social da Faculdade de Ciências Médicas da UNICAMP Campinas, SP; Departamento de Medicina Preventiva e Social da Faculdade de Medicina da Universidade Federal de Minas Gerais (UFMG)

** Departamento de Medicina Preventiva e Social da Faculdade de Medicina da Universidade Federal de Minas Gerais (UFMG) - Belo Horizonte, MG - Brasil.

Separatas/Reprints: R.Mendes - Av. Alfredo Belena, 190 - $10^{\circ}$ andar - 30130 - Belo Horizonte, MG - Brasil.

Publicação finaciada pela FAPESP. Processo Medicina 90/4602-1
- Quais as principais características da saúde do trabalhador?

Muitas outras perguntas não menos importantes, tanto de natureza epistemológica quanto prospectiva, poderiam ser formuladas. Contudo, no presente trabalho, a análise se restringirá a estas.

\section{Principais características da medicina do trabalho}

A medicina do trabalho, enquanto especialidade médica, surge na Inglaterra, na primeira metade do século XIX, com a Revolução Industrial ${ }^{56}$.

Naquele momento, o consumo da força de trabalho, resultante da submissão dos trabalhadores a um processo acelerado e desumano de produção, exigiu uma intervenção, sob pena de tornar inviável a sobrevivência e reprodução do próprio processo.

Quando Robert Dernham, proprietário de uma fábrica textil, preocupado com o fato de que seus operários não dispunham de nenhum cuidado médico a não ser aquele propiciado por instituições filantrópicas, procurou o Dr. Robert Baker, seu médico, pedindo que indicasse qual a maneira pela qual ele, como empresário, poderia resolver tal situação, Baker respondeu-lhe:

"Coloque no interior da sua fábrica o seu próprio médico, que servirá de intermediário entre você, os seus trabalhadores e o público. Deixe-o visitar a fábrica, sala por sala, sempre que existam pessoas trabalhando, de maneira que ele possa verificar o efeito do trabalho sobre as pessoas. E se ele verificar que qualquer dos trabalhadores está sofrendo a influência de causas que possam ser prevenidas, a ele competirá fazer tal prevenção. Dessa forma você poderá dizer: meu médico é a minha defesa, pois a ele dei toda a minha autoridade no que diz respeito à proteção da saúde e das condições físicas dos meus operários; se algum deles vier a sofrer qualquer alteração da saúde, o médico unicamente é que deve ser responsabilizado".

(1) Série comemorativa do $25^{\circ}$ aniversário da Revista de Saúde Pública 
A resposta do empregador foi a de contratar Baker para trabalhar na sua fábrica, surgindo assim, em 1830 , o primeiro serviço de medicina do trabalho ${ }^{40}$.

$\mathrm{Na}$ verdade, despontam na resposta do fundador do primeiro serviço médico de empresa, os elementos básicos da expectativa do capital quanto às finalidades de tais serviços:

- deveriam ser serviços dirigidos por pessoas de inteira confiança do empresário e que se dispusessem a defendê-lo;

- deveriam ser serviços centrados na figura do médico;

- a prevenção dos danos à saúde resultantes dos riscos do trabalho deveria ser tarefa eminentemente médica;

- a responsabilidade pela ocorrência dos problemas de saúde ficava transferida ao médico.

A implantação de serviços baseados neste modelo rapidamente expandiu-se por outros países, paralelamente ao processo de industrialização e, posteriormente, aos países periféricos, com a transnacionalização da economia. A inexistência ou fragilidade dos sistemas de assistência à saúde, quer como expressão do seguro social, quer diretamente providos pelo Estado, via serviços de saúde pública, fez com que os serviços médicos de empresa passassem a exercer um papel vicariante, consolidando, ao mesmo tempo, sua vocação enquanto instrumento de criar e manter a dependência do trabalhador (e frequientemente também de seus familiares), ao lado do exercício direto do controle da força de trabalho.

A preocupação por prover serviços médicos aos trabalhadores começa a se refletir no cenário internacional também na agenda da Organização Internacional-do Trabalho (OIT), criada em 1919. Assim, em 1953, através da Recomendação 97 sobre a "Proteção da Saúde dos Trabalhadores", a Conferência Internacional do Trabalho instava aos Estados Membros da OIT que fomentassem a formação de médicos do trabalho qualificados e o estudo da organização de "Serviços de Medicina do Trabalho". Em 1954, a OIT convocou um grupo de especialistas para estudar as diretrizes gerais da organização de "Serviços Médicos do Trabalho". Dois anos mais tarde, o Conselho de Administração da OIT, ao inscrever o tema na ordem-do-dia da Conferência Internacional do Trabalho de 1958, substituiu a denominação "Serviços Médicos do Trabalho" por "Serviços de Medicina do Trabalho".

Com efeito, em 1959, a experiência dos países industrializados transformou-se na Recomendação $112^{45}$, sobre "Serviços de Medicina do Trabalho", aprovada pela Conferência Internacional do Trabalho. Este primeiro instrumento normativo de âmbito internacional passou a servir como referencial e paradigma para o estabelecimento de diplomas legais nacionais (onde aliás, baseia-se a norma brasi- leira). Aborda aspectos que incluem a sua definição, os métodos de aplicação da Recomendação, a organização dos Serviços, suas funções, pessoal e instalações, e meios de ação $0^{45}$.

Segundo a Recomendação $112^{45}$, "a expressão 'serviço de medicina do trabalho' designa um serviço organizado nos locais de trabalho ou em suas imediações, destinado a:

- assegurar a proteção dos trabalhadores contra todo o risco que prejudique a sua saúde e que possa resultar de seu trabalho ou das condições em que este se efetue;

- contribuir à adaptação física e mental dos trabalhadores, em particular pela adequação do trabalho e pela sua colocação em lugares de trabalho correspondentes às suas aptidões;

- contribuir ao estabelecimento e manutenção do nível mais elevado possível do bem-estar físico e mental dos trabalhadores"45.

Desta conceituação podem ser extraídas mais algumas características da medicina do trabalho (além das anteriormente identificadas, a propósito de sua origem), assim como alguns questionamentos que têm a ver com suas limitações, a saber:

- A medicina do trabalho constitui fundamentalmente uma atividade médica, e o "locus" de sua prática dá-se tipicamente nos locais de trabalho.

- Faz parte de sua razão de ser a tarefa de cuidar da "adaptação física e mental dos trabalhadores", supostamente contribuindo na colocação destes em lugares ou tarefas correspondentes às aptidões. A "adequação do trabalho ao trabalhador", limitada à intervenção médica, restringe-se à seleção de candidatos a emprego e à tentativa de adaptar os trabalhadores às suas condições de trabalho, através de atividades educativas.

- Atribui-se à medicina do trabalho a tarefa de "contribuir ao estabelecimento e manutenção do nivel mais elevado possível do bem-estar físico e mental dos trabalhadores", conferindo-lhe um caráter de onipotência, próprio da concepção positivista da prática médica.

Esta visão de onipotência da medicina fica exemplificada no discurso de Selby ${ }^{57}$, em 1939, quando ao tratar da finalidade e da organização dos serviços médicos de empresa, afirmava:

"It is the plant physician's privilege and duty to cooperate (...) to conserve human values..."

ou nas palavras de Townsend ${ }^{59}$, em 1943:

"[Occupational Medicine] is concerned with every phase of the health of the man behind the machine, wheter it is the industrial dust in the air he breathes or the food his wife has packed in his dinner pail. In short, it is the problem of keeping the worker on the 
job, and in good health, so that he can work at the top efficiency."

Aliás, tanto a expectativa de promover a "adaptação" do trabalhador ao trabalho, quanto a da "manutenção de sua saúde", refletem a influência do pensamento mecanicista na medicina científica e na fisiologia. No campo das ciências da administração, o mecanicismo vai sustentar o desenvolvimento da "Administração Científica do Trabalho", onde os princípios de Taylor, ampliados por Ford, encontram na medicina do trabalho uma aliada para a perseguição do seu "telos" último: a produtividade".

Não é ao acaso que a Henry Ford tenha sido atribuída a declaração de que "o corpo médico é a seção de minha fábrica que me dá mais lucro" (citada por Oliveira e Teixeira ${ }^{44}$ ).

A explicação é dada por Oliveira e Teixeira ${ }^{44}$ com as seguintes palavras:

"Em primeiro lugar, a seleção de pessoal, possibilitando a escolha de uma mão-de-obra provavelmente menos geradora de problemas futuros como o absentismo e suas consequiências (interrupção da produção, gastos com obrigações sociais, etc.). Em segundo lugar, o controle deste absentismo na força de trabalho já empregada, analisando os casos de doenças, faltas, licenças, obviamente com mais cuidado e maior controle por parte da empresa do que quando esta função é desempenhada por serviços médicos externos a ela, por exemplo, da Previdência Social. Outro aspecto é a possibilidade de obter um retorno mais rápido da força de trabalho à produção, na medida em que um serviço próprio tem a possibilidade de um funcionamento mais eficaz nesse sentido, do que habitualmente 'morosas' e 'deficientes' redes previdenciárias e estatais, ou mesmo a prática liberal sem articulação com a empresa."

\section{Como e por que evoluiu a medicina do trabalho para a saúde ocupacional?}

O preço pago pelos trabalhadores em permanecer nas indústrias durante os anos da II Guerra Mundial, .em condições extremamente adversas e em intensidade de trabalho extenuante, foi - em algumas categorias - tão pesado e doloroso quanto o da própria guerra. Sobretudo porque, terminado o conflito béli$\mathrm{co}$, o gigantesco esforço industrial do pós-guerra estava recém iniciando.

Num contexto econômico e político como o da guerra e o do pós-guerra, o custo provocado pela perda de vidas - abruptamente por acidentes do trabalho, ou mais insidiosamente por doenças do trabalho - começou a ser também sentido tanto pelos empregadores (ávidos de mão-de-obra produtiva), quanto pelas companhias de seguro, às voltas com o pagamento de pesadas indenizações por incapacidade provocada pelo trabalho.
A tecnologia industrial evoluira de forma acelerada, traduzida pelo desenvolvimento de novos processos industriais, novos equipamentos, e pela síntese de novos produtos químicos, simultaneamente ao rearranjo de uma nova divisão internacional do trabalho.

Entre muitos outros desdobramentos deste processo, desvela-se a relativa impotência da medicina do trabalho para intervir sobre os problemas de saúde causados pelos processos de produção. Crescem a insatisfação e o questionamento dos trabalhadores - ainda que apenas 'objeto' das ações - e dos empregadores, onerados pelos custos diretos e indiretos dos agravos à saúde de seus empregados.

A resposta, racional, "científica" e aparentemente inquestionável traduz-se na ampliação da atuação médica direcionada ao trabalhador, pela intervenção sobre o ambiente, com o instrumental oferecido por outras disciplinas e outras profissões.

A "Saúde Ocupacional" surge, sobretudo, dentro das grandes empresas, com o traço da multi e interdisciplinaridade, com a organização de equipes progressivamente multi-profissionais, e a ênfase na higiene "industrial", refletindo a origem histórica dos serviços médicos e o lugar de destaque da indústria nos países "industrializados"..

Nada mais oportuno que citar, textualmente, esta característica inovadora da saúde ocupacional, nas palavras de Hussey ${ }^{26}$ quando, em 1947, discutia um artigo sobre o lugar da engenharia na saúde ocupacional:

"This whole subject of Occupational Health is analogous to a three-legged stool, one leg representing medical science, one representing engineering and chemical science and one representing social sciences...Up to the present we have been trying to balance ourselves on two legs and in some instances on one leg. It is a very uncomfortable position and one that cannot get us very far and certainly will lead, as it has, to fatigue."

A racionalidade "científica" da atuação multiprofissional e a estratégia de intervir nos locais de trabalho, com a finalidade de controlar os riscos ambientais, refletem a influência das escolas de saúde pública, onde as questões de saúde e trabalho já vinham sendo estudadas há algum tempo. Na metade deste século intensificam-se o ensino e a pesquisa dos problemas de saúde ocupacional nas escolas de saúde pública - principalmente nos Estados Unidos (Harvard, Johns Hopkins, Michigan, e Pittsburgh) - com forte matiz ambiental.

Assim, de um lado a saúde ocupacional passa a ser considerada como um ramo da saúde ambiental (como, aliás aconteceu também na Faculdade de Saúde Pública da Universidade de São Paulo); de 
outro, desenvolvem-se fortes unidades de higiene "industrial", através de "grants" e contratos de serviços com grandes empresas. No estabelecimento da higiene ocupacional nestes centros acadêmicos e em instituições governamentais de projeção, os nomes de Theodore Hatch, Phillip Drinker, Herbert Stokinger e John Bloomfield, entre outros, passam a constituir referência obrigatória ${ }^{3,56}$.

Contudo, o desenvolvimento da saúde ambiental/ saúde ocupacional nas escolas de saúde pública dos Estados Unidos, centrado na higiene ocupacional, deu-se, não de forma complementar, mas acompanhado de uma relativa desqualificação do enfoque médico e epidemiológico da relação trabalho-saúde.

Vale lembrar que havia sido Alice Hamilton médica pioneira nos estudos das doenças profissionais - quem dera, de 1919 a 1935, projeção à Universidade Harvard, ao enfocar os problemas de saúde do trabalhador sob o ângulo médicoepidemiológico. Assim fez Anna Baetjer, que por mais de 60 anos dedicou-se aos estudos da patologia do trabalho na Escola de Saúde Pública da Universidade Johns Hopkins. E assim foi com muitos outros centros 3.24 .25 .56 .

No Brasil, a adoção e o desenvolvimento da saúde ocupacional deram-se tardiamente, estendendose em várias direções. Reproduzem, aliás, o processo ocorrido nos países do Primeiro Mundo.

Na vertente acadêmica, destaca-se a Faculdade de Saúde Pública da Universidade de São Paulo, que dentro do Departamento de Saúde Ambiental, cria uma "área de Saúde Ocupacional", e estende de forma especial sua influência como centro irradiador do conhecimento, via cursos de especialização e, principalmente, via pós-graduação (mestrado e doutorado). Com efeito, este modelo foi reproduzido em outras instituições de ensino e pesquisa, em especial em nivel de alguns departamentos de medicina preventiva e social de escolas médicas.

Nas instituições, a marca mais característica expressa-se na criação da Fundação Jorge Duprat Figueiredo de Segurança e Medicina do Trabalho (FUNDACENTRO), versão nacional dos modelos de "Institutos" de Saúde Ocupacional desenvolvidos no exterior, a partir da década de 50, entre eles, os de Helsinque, Estocolmo, Praga, Budapeste, Zagreb, Madrid, o NIOSH em Cincinnati, Lima e de Santiago do Chile.

$\mathrm{Na}$ legislação, expressou-se na regulamentação do Capítulo $\mathrm{V}$ da Consolidação das Leis do Trabalho (CLT), reformada na década de 70, principalmente nas normas relativas à obrigatoriedade de equipes técnicas multidisciplinares nos locais de trabalho (atual Norma Regulamentadora 4 da Portaria 3214/ 78); na avaliação quantitativa de riscos ambientais e adoção de "limites de tolerância" (Normas Regulamentadoras 7 e 15), entre outras. Apesar das mudanças estabelecidas na legislação trabalhista, foram mantidas na legislação previdenciária/ acidentária as características básicas de uma prática medicalizada, de cunho individual, e voltada exclusivamente para os trabalhadores engajados no setor formal de trabalho.

Caberia, ao encerrar esta parte, saber porque o modelo da saúde ocupacional - desenvolvido para atender a uma necessidade da produção - não conseguiu atingir os objetivos propostos. Dentre os fatores que poderiam ser listados para explicar sua insuficiência, estão:

- o modelo mantém o referencial da medicina do trabalho firmado no mecanicismo;

- não concretiza o apelo à interdisciplinaridade: as atividades apenas se justapõem de maneira desarticulada e são dificultadas pelas lutas corporativas;

- a capacitação de recursos humanos, a produção de conhecimento e de tecnologia de intervenção não acompanham o ritmo da transformação dos processos de trabalho;

- o modelo, apesar de enfocar a questão no coletivo de trabalhadores, continua a abordá-los como "objeto" das ações de saúde;

- a manutenção da saúde ocupacional no âmbito do trabalho, em detrimento do setor saúde.

\section{A insuficiência da saúde ocupacional e 0 surgimento da saúde do trabalhador.}

A insuficiência do modelo da saúde ocupacional não constitui fenômeno pontual e isolado. Antes, foi e continua sendo um processo que, embora guarde uma certa especificidade do campo das relações entre trabalho e saúde, tem sua origem e desenvolvimento determinados por cenários políticos e sociais mais amplos e complexos.

Além disto, ainda que este processo tenha traços comuns que lhe conferem uma certa universalidade, ele ocorre em ritmo e natureza próprios, refletindo a diversidade dos mundos políticos e sociais, e as distintas maneiras de os setores trabalho e saúde se organizarem.

Em que cenário a insuficiência deste modelo se evidencia?

Um movimento social renovado, revigorado e redirecionado surge nos países industrializados do mundo ocidental - notadamente Alemanha, França, Inglaterra, Estados Unidos e Itália - mas que se espraia mundo afora. São os anos da segunda metade da década de 60, (maio de 1968 tipifica a exteriorização deste fenômeno) marcados pelo questionamento do sentido da vida, o valor da liberdade, o significado do trabalho na vida, o uso do corpo, e a denúncia do obsoletismo de valores já sem significado para a nova geração. Estes questionamentos abalaram a confiança no Estado e 
puseram em xeque o lado "sagrado" e "místico" do trabalho - cultivado no pensamento cristão e necessário na sociedade capitalista.

Este processo leva, em alguns países, à exigência da participação dos trabalhadores nas questões de saúde e segurança. Elas, mais que quaisquer outras, tipificavam situações concretas do cotidiano dos trabaIhadores, expressas em sofrimento, doença e morte ${ }^{5,53}$.

Como resposta ao movimento social e dos trabalhadores, novas políticas sociais tomam a roupagem de lei, introduzindo significativas mudanças na legislação do trabalho e, em especial, nos aspectos de saúde e segurança do trabalhador. Assim, por exemplo, na Itália, a Lei 300 , de 20 de maio de 1970 ("Norme per la libertá e la dignitá dei lavoratori, della libertá sindicale e dell'attivitá sindicale nei luoghi di lavoro"), mais conhecida como "Estatuto dos Trabalhadores", incorpora princípios fundamentais da agenda do movimento de trabalhadores, tais como a não delegação da vigilância da saúde ao Estado, a não monetização do risco, a validação do saber dos trabalhadores e a realização de estudos e investigações independentes, o acompanhamento da fiscalização, e o melhoramento das condições e dos ambientes de trabalho $0^{1.4 .36 .46 .51}$.

Conquistas básicas de natureza semelhante, com algumas peculiaridades próprias de contextos político-sociais distintos, foram também sendo alcançados pelos trabalhadores norte-americanos (a partir da nova lei de 1970), ingleses (a partir de 1974), suecos (a partir de 1974), franceses (a partir de 1976), noruegueses (1977), canadenses (1978), entre outros ${ }^{36,46.55}$.

Toda esta nova legislação tem como pilares comuns o reconhecimento do exercício de direitos fundamentais dos trabalhadores, entre eles, o direito à informação (sobre a natureza dos riscos, as medidas de controle que estão sendo adotadas pelo empregador, os resultados de exames médicos e de avaliações ambientais, e outros; o direito à recusa ao trabalho em condições de risco grave para a saúde ou a vida; o direito à consulta prévia aos trabalhadores, pelos empregadores, antes de mudanças de tecnologia, métodos, processos e formas de organização do trabalho: e o estabelecimento de mecanismos de participação, desde a escolha de tecnologias, até, em alguns países, a escolha dos profissionais que irão atuar nos serviços de saúde no trabalho 1,3,5,43,46,51,55.

A década de 70 testemunha profundas mudanças nos processos de trabalho. Num sentido mais "macro", observa-se uma forte tendência de "terciarização" da economia dos países desenvolvidos, isto é, o início de declínio do setor secundário (indústria), e o crescimento acentuado do setor terciário (serviços), com óbvia mudança do perfil da força de trabalho empregada ${ }^{10,50}$.
Ocorre um processo de transferência de indústrias para o Terceiro Mundo, - uma verdadeira transnacionalização da economia - principalmente daquelas que provocam poluição ambiental ou risco para a saúde (ex.: asbesto, chumbo, agrotóxicos, e outros), e das que requerem muita mão-de-obra, com baixa tecnologia, como é o caso típico das "maquiladoras", que rapidamente se instalam nas "zonas livres" ou "francas", mundo afora. Os países do Terceiro Mundo, afligidos pela elevação dos preços do petróleo e pressionados pela recessão que se instala universalmente, buscam o desenvolvimento econômico a qualquer custo, aceitando e estimulando esta transferência, supostamente capaz de amenizar o desemprego e gerar divisas ${ }^{8,31,37}$.

Num nível mais "micro", observa-se a rápida implantação de novas tecnologias, entre as quais podem ser destacadas duas vertentes que se completam: a automação (máquinas de controle numérico, robots, e outros) e a informatizaçãa $o^{50,60}$.

Apesar de a automação e a informatização virem cercadas de uma certa aura mítica de se constituirem na "última palavra da ciência a serviço do homem", elas introduziram, na verdade, profundas modificações na organização do trabalho. Por exemplo, permitiram ao capital diminuir sua dependência dos trabalhadores, ao mesmo tempo em que aumentaram a possibilidade de controle. Ressurge, com vigor redobrado, o taylorismo, através de dois de seus princípios basicos: o da primazia da gerência (via apropriação do conhecimento operário e pela interferência direta nos métodos e processos), e o da importância do planejamento e controle do trabalho ${ }^{17,60}$.

Contudo, se de um lado o capital busca reeditar as bases da "administração científica do trabalho", agora mais sofisticada, de outro, abre espaço a formas de "resistência" desenvolvidas pelos trabalhadores. Como consequiência, são desenvolvidas, nos países escandinavos, experiências dos "grupos semiautônomos", na Volvo e Saab, numa perspectiva de ampliar a participação dos trabalhadores, diminuindo os enfrentamentos.

No campo das idéias sobre saúde, predominava, até os anos'70, a concepção positivista de que a Medicina teria ampla autonomia e estaria no mesmo nível que outros subsistemas - como o econômico, o político, o educacional - e a suposição de que seria possível transformar a sociedade a partir de qualquer desses setores ${ }^{20}$.

Esta visão de mundo sustenta a teoria da multicausalidade do processo saúde-doença, onde os fatores de risco do adoecer e morrer são considerados com o mesmo valor ou potencial de agressão ao homem, visto este como "hospedeiro". A prática da saúde ocupacional assenta-se sobre esta concepção. 
Entretanto, a partir do final dos anos' 60 , começam a aparecer críticas a esta concepção e a denúncia dos efeitos negativos da medicalização e do caráter ideológico e reprodutor das instituições médicas, com a proposta de desmedicalização da socieda$\mathrm{de}^{18.20,42}$.

No campo da prática médica, surgem programas alternativos de auto-cuidado de saúde, de assistência primária, de extensão de cobertura, de revitalização da medicina tradicional, uso de tecnologia simplificada, e ênfase na participação comunitária ${ }^{20}$.

Apesar da "apropriação" pelo Estado de algumas destas alternativas, surgidas da crítica às instituições médicas, e do fracasso relativo dessas medidas, elas revitalizam a discussão teórica sobre a articulação da saúde na sociedade ${ }^{20,42}$.

Nesse intenso processo social de discussões teóricas e de práticas alternativas, ganha corpo a teoria da determinaçâo social do processo saúde-doença, cuja centralidade colocada no trabalho - enquanto organizador da vida social - contribui para aumentar os questionamentos à medicina do trabalho e à saúde ocupacional ${ }^{15.30 .58}$.

As críticas tornam-se mais contundentes, à medida que surgem, em nivel da rede pública de serviços de saúde, programas de assistência aos trabalhadores, com ativa participação destes, e das suas organizações. Os programas contribuem para desvelar o impacto do trabalho sobre a saúde, questionam as práticas dos serviços de medicina do trabalho nas empresas e instrumentalizam os trabalhadores nas suas reivindicações por melhores condições de saú$\mathrm{de}^{13.15 .19 .32 .33 .41 .47 .58 \text {. }}$

Neste processo de questionamento da prática médica e gestação de uma nova prática, alguns pensadores tiveram papel de destaque. Entre eles, Polack ${ }^{48}$ com suas idéias radicais, de que "a medicina no modo de produção capitalista é a medicina do capital"; Berlinguer ${ }^{5}$, que trabalhou ativamente a questão da saúde do trabalhador no movimento da Reforma Sanitária italiana; e Foucault ${ }^{18.20}$, ao dissecar questões nevrálgicas da prática médica, desnudando o poder e o controle, tão bem representados na medicina do trabalho.

Quais as conseqüencias deste intenso processo social de mudanças sobre a aparente hegemonia do "modelo da saúde ocupacional"?

É possível identificar, entre outras:

- Os trabalhadores explicitam sua desconfiança nos procedimentos técnicos e éticos dos profissionais dos serviços de saúde ocupacional (segurança, higiene e medicina do trabalho); estes têm uma enorme dificuldade em lidar com o "novo", mormente naquilo que significou perda de poder e hegemonia ${ }^{5.16 .39 .51}$.

- O exercício da participaçáo do trabalhador em questões de saúde pôs em xeque, em muitos casos, conceitos e procedimentos amplamente consagrados pela saúde ocupacional, como por exemplo, o valor e a ética de exames médicos pré-admissionais e periódicos, utilizados, segundo a denúncia dos trabalhadores, para práticas altamente discriminatórias ${ }^{28}$.

- Desmorona o mito dos "limites de tolerância" que fundamentou a lógica da saúde ocupacional (principalmente higiene e toxicologia) por mais de 50 anos. A fundamentação científica é questionada (para não dizer desmoralizada); o conceito de "exposição segura" é abalado; e os estudos de efeitos comportamentais provocados pela exposição a baixas doses de chumbo e de solventes orgânicos, põem em xeque os critérios de "proteção de saúde" que vigiram nos países industrializados ocidentais até há pouco 6.9 .14 .21 .29 .54 .

- À medida em que a organização do trabalho amplia sua importância na relação trabalho/saúde, requerem-se novas estratégias para a modificação de condições de trabalho, que "atropelam" a Saúde Ocupacional (até então trabalhando na lógica "ambiental")"23.

- A utilização de novas tecnologias - em especial as que introduzem a automação e a informatizaşăo nos processos de trabalho - embora possa contribuir para o melhoramento das condições de trabalho. acabam introduzindo novos riscos à saúde, quase sempre decorrentes da organização do trabalho, e portanto, de difícil "medicalização"

- As modificações dos processos de trabalho em nível "macro" (terciarização da economia), e "micro" (automação e informatização), acrescentados à eliminação dos riscos nas antigas condições de trabalho, provocam um deslocamento do perfil de morbidade causada pelo trabalho: as doenças profissionais clássicas tendem a desaparecer, e a preocupação desloca-se para as outras "doenças relacionadas com o trabalho" (work related diseases). Passam a ser valorizadas as doenças cardiovasculares (hipertensão arterial e doença coronariana), os distúrbios mentais, o estresse e o câncer, entre outras. Desloca-se, assim, a vocação da saúde ocupacional, passando esta a se ocupar da "promoção de saúde", cuja estratégia principal é a de, através de um processo de educação, modificar o comportamento das pessoas e seu "estilo de vida" 10.22 .34 .35 .

- Na verdade, esta nova exigência colocada à saúde ocupacional nos países desenvolvidos e nas grandes corporações no Terceiro Mundo, se superpõe àquelas existentes na imensa maioria dos estabelecimentos de trabalho (pequenos e médios) e na economia informal, onde permanecem as condições de risco para a saúde dos trabalhadores, com os problemas clássicos e graves, até hoje não solucionados pelos modelos utilizados. 


\section{Características da saúde do trabalhador}

Do intenso processo social de mudança, ocorrido no mundo ocidental nos últimos vinte anos, foram mencionados, anteriormente, alguns aspectos que, no âmbito das relações trabalho $x$ saúde, conformaram a saúde do trabalhador.

Como característica básica desta nova prática, destaca-se a de ser um campo em construção no espaço da saúde pública. Assim, sua descrição constitui, antes, uma tentativa de aproximação de um objeto e de uma prática, com vistas a contribuir para sua consolidação enquanto área ${ }^{19,58}$.

O objeto da saúde do trabalhador pode ser definido como o processo saúde e doença dos grupos humanos, em sua relação com o trabalho. Representa um esforço de compreensão deste processo - como e porque ocorre - e do desenvolvimento de alternativas de intervenção que levem à transformação em direção à apropriação pelos trabalhadores, da dimensão humana do trabalho, numa perspectiva teleológica.

Nessa trajetória, a saúde do trabalhador rompe com a concepção hegemônica que estabelece um vínculo causal entre a doença e um agente específico, ou a um grupo de fatores de risco presentes no ambiente de trabalho e tenta superar o enfoque que situa sua determinação no social, reduzido ao processo produtivo, desconsiderando a subjetivida-

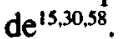

Apesar das dificuldades teórico-metodológicas enfrentadas, a saúde do trabalhador busca a explicação sobre o adoecer e o morrer das pessoas, dos trabalhadores em particular, através do estudo dos processos de trabalho, de forma articulada com o conjunto de valores, crenças e idéias, as representações sociais, e a possibilidade de consumo de bens e serviços, na "moderna" civilização urbano-industrial $^{15}$.

Nessa perspectiva, e com as limitações assinaladas, a saúde do trabalhador considera o trabalho, enquanto organizador da vida social, como o espaço de dominação e submissão do trabalhador pelo capital, mas, igualmente, de resistência, de constituição, e do fazer histórico. Nesta história os trabalhadores assumem o papel de atores, de sujeitos capazes de pensar e de se pensarem, produzindo uma experiência própria, no conjunto das representações da sociedade ${ }^{15,53}$.

No âmbito das relações saúde $\mathrm{x}$ trabalho, os trabalhadores buscam o controle sobre as condiçōes e os ambientes de trabalho, para torná-los mais "saudáveis". É um processo lento, contraditório, desigual no conjunto da classe trabalhadora, dependente de sua inserção no processo produtivo e do contexto sócio-político de uma determinada sociedade ${ }^{43,53}$.

Assim, a saúde do trabalhador apresenta expres- sões diferentes segundo a época e o país, e diferenciada dentro do próprio país, como pode ser observado na Itália, na Escandinávia, no Canadá, ou no Brasil. Porém, apesar das diferenças, mantém os mesmos princípios - trabalhadores buscam ser reconhecidos em seu saber, questionam as alterações nos processos de trabalho, particularmente a adoção de novas tecnologias, exercitam o direitto à informação e a recusa ao trabalho perigoso ou arriscado à saú$\mathrm{de}^{1,4,5,43,46}$

$\mathrm{Na}$ implementação deste "novo" modo de lidar com as questões de saúde relacionadas ao trabalho, os trabalhadores contam com dois apoios importantes: uma assessoria técnica especializada e o suporte, ainda que limitado, dos serviços públicos estatais de saúde.

No Brasil surge a assessoria sindical feita por profissionais comprometidos com a luta dos trabalhadores, que individualmente ou através de organizações como o Departamento Intersindical de Estudos e Pesquisas de Saúde e dos Ambientes de Trabalho (DIESAT) e o Instituto Nacional de Saúde no Trabalho (INST), no caso do Brasil, estudando os ambientes e condições de trabalho, levantando riscos e constatando danos para a saúde; decodificando o saber acumulado, num processo contínuo de socialização da informação; resgatando e sistematizando o saber operário, vivenciando, na essência, a relação pedagógica educador-educando ${ }^{16,27,52}$.

Também pode ser constatada a contribuição ao desenvolvimento da área de saúde do trabalhador, trazida pelos técnicos que em nível das instituições públicas - as Universidades e Institutos de Pesquisa, a rede de Serviços de Saúde e fiscalização do trabalho - somam esforços na luta por melhores condições de saúde e trabalho, através da capacitação profissional, da produção do conhecimento, da prestação de serviços e da fiscalização das exigências legais ${ }^{13.19 .47 .58}$.

Como características desta "nova prática" cabe ainda mencionar o esforço que vem sendo empreendido no campo da saúde do trabalhador para integrar as dimensões do individual $\mathrm{x}$ coletivo, do biológico $\mathrm{x}$ social, do técnico $\mathrm{x}$ político, do particular $\mathrm{x}$ geral. $E$ um exercício fascinante, ao qual têm se dedicado os profissionais de saúde e os trabalhadores, que parece apontar uma saída para a grave crise da "ciência médica" ou das "ciências da saúde", neste final de século. Os cânones clássicos colocados a partir de formas fragmentadas de ver e estudar o mundo, se contribuiram para o aprofundamento do conhecimento em niveis inimagináveis, estão a necessitar de uma nova abordagem que consiga reuní-los, articulá-los, colocando-os a serviço dos homens.

No Brasil, a emergência da saúde do trabalhador pode ser identificada no início dos anos' 80 , no contexto da transição democrática, em sintonia com o que ocorre no mundo ocidental. 
Entre suas características básicas, destacam-se:

- Ganha corpo um novo pensar sobre o processo saúde-doença, e o papel exercido pelo trabalho na sua determinaçãa $0^{2,15,49,58}$

- Há o desvelamento circunscrito, porém inquestionável, de um adoecer e morrer dos trabalhadores, caracterizado por verdadeiras "epidemias", tanto de doenças profissionais clássicas (intoxicação por chumbo, mercúrio, benzeno, e a silicose), quanto de "novas" doenças relacionadas ao trabalho, como a LER (lesões por esforços repetitivos), por exemplo ${ }^{16,47,52}$.

- São denunciadas as políticas públicas e o sistema de saúde, incapazes de dar respostas às necessidades de saúde da população, e dos trabalhadores, em especial ${ }^{12,49}$.

- Surgem novas práticas sindicais em saúde, traduzidas em reivindicações de melhores condições de trabalho, através da ampliação do debate, circulação de informações, inclusão de, pautas específicas nas negociações coletivas, da reformulação do trabalho das Comissões Internas de Prevenção de Acidentes (CIPAs), no bojo da emergência do novo sindicalismo ${ }^{16,27}$.

Este processo social se desdobrou em uma série de iniciativas e se expressou nas discussões da VIII Conferência Nacional de Saúde, na realização da I Conferência Nacional de Saúde dos Trabalhadores, e foi decisivo para a mudança de enfoque estabelecida na nova Constituição Federal de 1988. Mais recentemente, a denominação "saúde do trabalhador" aparece, também, incorporada na nova Lei Orgânica de Saúde, que estabelece sua conceituação e define as competências do Sistema Unico de Saúde neste campo ${ }^{7,11,12,38}$.

À guisa de conclusão retoma-se a idéia expressa na Introdução deste ensaio.

A caminhada da medicina do trabalho à saúde do trabalhador encontra-se em processo. Sua história pode ser contada em diferentes versões, porém com a certeza de que é construída por homens que buscam viver. Livres.

MENDES, R. \& DIAS, E.C. [From occupational medicine to workers' health]. Rev. Saúde públ., S. Paulo, 25: $341-9,1991$. The evolution of the concepts and practice of occupational medicine, occupational health and workers' health is tentatively reviewed. An attemp is made to answer the following questions: what were the major characteristics of occupational medicine throughout its evolution? How and why did occupational medicine evolve into occupational health? Why has the "occupational health model" become inadequate? Writhin what context did workers' health arise? What are the principal characteristics of workers' health?

Keywords: Occupational health. Occupational medicine, history.

\section{Referências Bibliográficas}

1. ASSENATO, G. \& NAVARRO, V. Workers participation and control in Italy: the case of occupational medicine. Int. J. Hlth Serv., 10: 217-21, 1980.

2. ASSOCIAÇÃO BRASILEIRA DE PÓS-GRADUAÇÃO EM SAÚDE COLETIVA (ABRASCO). Saúde e trabalho-de. safios para uma política. Rio de Janeiro, 1990

3. BAETJER, A.M. The early days of Industrial Hygiene - their contribution to the current problems. Amer. industr. Hyg. Ass. J., 41: 773-77, 1980.

4. BAGNARA, S. et al. Trends in occupational health and safety in Italy. Int. J. Hlth Serv., 11: 431-50, 1981.

5. BERLINGUER, G. A saúde nas fábricas. São Paulo, Hucitec, 1978.

6. BLEECKER, M.L. et al. Dose-related subclinical neurobehavioral effects of chronic exposure to low levels of organic solvents. Amer. J. industr. Med., 19: 715-28, 1991.

7. BRASIL, Leis, etc. Lei $\mathrm{n}^{2} 8.080$ de 19 de setembro de 1990: dispõe sobre as condições para a promoção, proteção e recuperação da saúde, a organização e o funcionamento dos serviços correspondentes e dá outras providências. Diário Oficial da Uniāo, Brasilia, 20 set. 1990. Seção I, p. 18055 60.

8. CASTLEMAN, B.I. The export of hazardous factories to developing nations. Int. J. Hlth Serv., 9: 569-606, 1979.

9. CASTLEMAN, B.I. \& ZIEM, G.E. Corporate influence on threshold limit values. Amer. J. industr. Med, 13: 531-59, 1988.

10. CESANA, G. et al. Sorveglianza sanitaria e prevenzione nel terziario problematiche e prospettive. Med. Lav., 81: 262-72, 1990.

11. CONFERÊNCIA NACIONAL DE SAÚDE, 8*, Brasilia, 1986. Anais. Brasília, Centro de Documentação do Ministério da Saúde, 1987.

12. CONFERÊNCIA NACIONAL DE SAÚDE DOS TRABALHADORES, 1aㅗ Brasília, 1986. Relatório final. Brasilia, 1986

13. COSTA, D.F. et al. Programa de saúde dos trabalhadores; a experiência da zona norte: uma alternativa em saúde pública. São Paulo, Oboré, 1989.

14. CRANMER, J.M. \& GOLDBERG, L. Neurobehavioral effects of solvents Neurotoxicology, 7: 1-95, 1986.

15. DIAS, E.C. Fotografando os anos 80 . In: Buschinelli, J. et al., eds. Isto é trabalho de gente? Vidas. Trabalho e Saúde no Brasil. São Paulo, Cortez, 1991. [no prelo].

16. DEPARTAMENTO INTERSINDICAL DE ESTUDOS E PESQUISAS DE SAÚDE E DOS AMBIENTES DE TRABALHO (DIESAT). Insalubridade: morte lenta no trabalho. São Paulo, Oboré, 1989.

17. FLEURY, A.C.C. \& VARGAS, N., org. Organização do traba. lho. São Paulo, Atlas, 1987.

18. FOUCAUT, M. História de la medicalización. Educ. med. Salud., 11: 1-25, 1977.

19. FREITAS, C.U. et al. Saúde pública e ações de saúde do trabalhador: uma análise conceitual e perspectivas de operacionalização programática na rede básica da Secretaria de Estado da Saúde. Temas IMESC. Soc. Dir. Saúde, 2 (1): 3 10, 1985.

20. GARCIA, J.C. Medicina \& sociedad: las corrientes de pensamiento en el campo de la salud. Educ. med. Salud, 17: 363-97, 1983.

21. GOLDSMITH, J.B. Perspective on what we formerly called threshold limit values. Amer. J. industr. Med., 19: 805-12, 1991.

22. GREEN, I.W. \& KREUTER, L.W. Health promotion as a public health strategy for the 1990s. Ann. Rev. publ. Hlth, 11: 319 . 34, 1990.

23. GUSTAVSEN, B. Mejoras del medio ambiente de trabajo: una nueva estrategia? Rev. Int. Trab., 99 (2): 173-88, 1980.

24. HAMILTON, A. Exploring the dangerous trades. 2nd ed. Boston, Northeastem University Press, 1985. 
25. HAMILTON, A. Forty years in the poisonous trades. Amer. $J$. Med., 7: 3-18, 1985.

26. HUSSEY, B. Engineering in industrial health education (Discussion). Occup. Med., 4: 204, 1947.

27. INSTITUTO NACIONAL DE SAÚDE NO TRABALHO. CUT avança na luta pela saúde no trabalho. Informat. INST, 1 (1): 1, 1990.

28. KENNEDY, S.M. Medical screening for occupational disease risk is not a control measure. Amer. J. industr. Med., 20 271-2, 1991.

29. LANDRIGAN, P.J. et al. Neuropsychological dysfunction in children with chronic low-level lead absorption. Lancet. 1: 708-12, 1975.

30. LAURELL, A.C. \& NORIEGA, M. Processo de produção e saúde: trabalho e desgaste operário. São Paulo. Hucitec, 1989.

31. MEDICI, A.C. Saúde e crise na América Latina (Impactos sociais e políticas de ajuste). Rev. Adm. púhl.. 23 (3): 7 $98,1989$.

32. MENDES, R. Doutrina e prática da integração da saúde ocupacional no setor saúde: contribuição para a definição de uma política. São Paulo, 1986. [Tese de Livre Docência - Faculdade de Saúde Pública da USPI.

33. MENDES, R. Subsídios para um debate em torno da revisão do atual modelo de organização da saúde ocupacional no Brasil. Rev, bras. Saúde ocup., 16 (64): 7.25, 1988.

34. MENDES, R. O impacto dos efeitos da ocupação sobre a saúde de trabalhadores. I - Morbidade. Rev. Saúde públ. S. Paulo, 22: 311-26, 1988 .

35. MENDES. R. O impacto dos efeitos da ocupação sobre a saúde de trabalhadores. II - Mortalidade. Rev. Saúde públ. S. Paulo, 22: 441-57, 1988.

36. MENDES, R. A prática da integração da saúde ocupacional no setor saúde: análise de alguns modelos estrangeiros. Rev. hras. Saíde ocup., 17 (65): 7-15, 1988.

37. MICHAELS, D. et al. O desenvolvimento econômico e a saúde na América Latina: novas tendências para a saúde pública em países subdesenvolvidos. Rev. bras. Saúde ocup., 13 (51): 7-14, 1985.

38. MINISTÉRIO DA SAUUDE. Saúde do trabalhador: diretrizes de ação para o SUS. Brasília, 1991. [Mimeografado].

39. MIRANDA, C.R. Medicina do trabalho: sua prática e seu mercado de trabalho no Estado da Bahia. Salvador, 1990. [Dissertação de Mestrado - Faculdade de Medicina da UFBA].

40. NOGUEIRA, D.P. A saúde dos trabalhadores e a empresa. São Paulo, s.d. [Mimeografado].

41. NOGUEIRA, D.P. Incorporação da saúde ocupacional à rede primária de saúde. Rev. Saúde públ.. S. Paulo, 18: 495$509,1984$.

42. NUNES, E.D., org. As ciências sociais em saúde na América Latina: tendências e perspectivas. Brasília, Organização Panamericana da Saúde. 1985.
43. ODDONE, I. et al. Ambiente de rabalho: a luta dos trabalhadores pela saúde. São Paulo, Hucitec, 1986.

44. OLIVEIRA, J.A.A. \& TEIXEIRA, S.M.F. (Im) Previdência Social; 60 anos de história da previdência no Brasil. Petrópolis, Vozes, 1986.

45. ORGANIZAÇÃO INTERNACIONAL DO TRABALHO. Recomendación sobre los servicios de Medicina del Trabajo en los lugares de empleo (Recomendación $n^{n} 112$ de la OIT adoptada en 24 de junio de 1959). In: Convenios y recomendaciones (19/9-1966). Genebra, 1966. p. 1054-8.

46. PARMEGGIANI, L. A nova legislaçāo de segurança e saúde dos trabalhadores. Rev. bras. Saúde ocup., 15 (50): 19.27, 1985.

47. PIMENTA, A.L. \& CAPISTRANO FILHO, D., org. Saúde do Irabalhador. Săo Paulo, Hucitec, 1988.

48. POLACK, J.C. La medicine du Capital. Paris, François Maspero. 1971.

49. POSSAS, C.A. Epidemiologia e sociedade: heterogeneidade estrutural e saúde no Brasil. São Paulo, Hucitec, 1989.

50. PROGRAMA REGIONAL DE EMPREGO PARA AMÉRICA LATINA E CARIBE (PREALC) Cambio tecnológico: empleo y trabajo. Santiago, PREALC, 1989. [Documentos de trabajo, 333].

51. REICH, M.R. \& GOLDMAN, R.H. Italian occupational health: concepts, conflicts; implications. Amer. J. publ. Hlth. 74: $1031-41,1984$

52. RIBEIRO, H.P. \& LACAZ, F.A.C., org. De que adoecem e morrem os trahalhadores. São Paulo, DIESAT, 1984.

53. RIGOTTO, R.M. A saúde do trabalhador como campo de luta. Belo Horizonte, 1990. [Mimeografado].

54. ROACH, S.A. \& RAPPAPORT, S.M. But they are not thresholds: a critical analysis of the documentation of threshold limit values. Amer. J. industr. Med., 17: 727-53, 1990.

55. ROUSTANG, G. Os trabalhadores e a higiene e segurança na França. Rev. bras. Saúde ocup., 13 (5): 40-6, 1985.

56. SCHILLING, R.S.F. Developments in occupational health. In: Schilling, R.S.F., ed. Occupational health practice. 2 nd ed. London, Butherworths, 1981. p. 3-26.

57. SELBY, C.D. Scope and organization of health service in industry. In: Lanza, A.J. \& Goldberg. J.A, eds. Industrial higiene. New York, Oxford University Press, 1939. p. 4.

58. TAMBELLINI, A.T. Da medicina do trabalho à saúde dos trabalhadores. In: Congresso da Associação Nacional de Medicina do Trabalho, $5^{\circ}$, Florianópolis, 1987. Anais. Florianópolis. ANAMT, 1987. p. 39-60.

59. TOWNSEND, J.G. The problem of industrial hygiene. New Orleans Med. Surg. J., 95: 505-12, 1943.

60. ZIDAN, L.N. Repercussōes da introdução de novas tecnologias e automação nas condiçōes de trabalho no Brasil. São Paulo, s.d. [Mimeografado].

Recebido para publicação em 16/09/1991. 